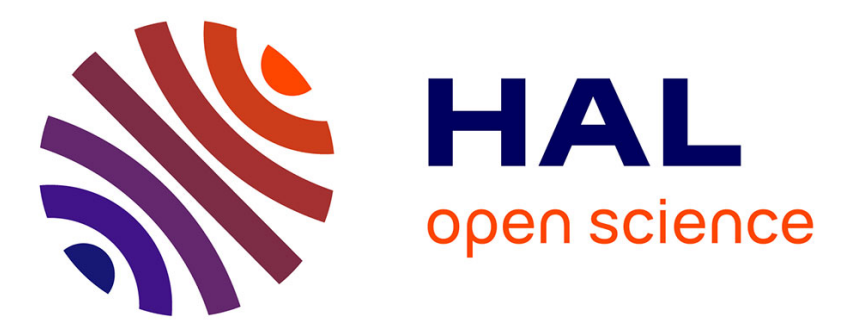

\title{
In-vivo analysis of sternal angle, sternal and sternocostal kinematics in supine humans during breathing
}

Benoît Beyer, Véronique Feipel, Victor Sholukha, Laurence Cheze, Serge van Sint Jan

\section{- To cite this version:}

Benoît Beyer, Véronique Feipel, Victor Sholukha, Laurence Cheze, Serge van Sint Jan. In-vivo analysis of sternal angle, sternal and sternocostal kinematics in supine humans during breathing. Journal of Biomechanics, 2017, 64, pp.32-40. 10.1016/j.jbiomech.2017.08.026 . hal-01652754

\section{HAL Id: hal-01652754 https://hal.science/hal-01652754}

Submitted on 30 Nov 2017

HAL is a multi-disciplinary open access archive for the deposit and dissemination of scientific research documents, whether they are published or not. The documents may come from teaching and research institutions in France or abroad, or from public or private research centers.
L'archive ouverte pluridisciplinaire HAL, est destinée au dépôt et à la diffusion de documents scientifiques de niveau recherche, publiés ou non, émanant des établissements d'enseignement et de recherche français ou étrangers, des laboratoires publics ou privés. 


\section{Accepted Manuscript}

In-vivo analysis of sternal angle, sternal and sternocostal kinematics in supine humans during breathing.

Benoît Beyer, Véronique Feipel, Victor Sholukha, Laurence Chèze, Serge Van Sint Jan.

PII: S0021-9290(17)30448-7

DOI: http://dx.doi.org/10.1016/j.jbiomech.2017.08.026

Reference: BM 8352

To appear in:

Journal of Biomechanics

Accepted Date:

25 August 2017

Please cite this article as: B. Beyer, V. Feipel, V. Sholukha, L. Chèze, S. Van Sint Jan., In-vivo analysis of sternal angle, sternal and sternocostal kinematics in supine humans during breathing., Journal of Biomechanics (2017), doi: http://dx.doi.org/10.1016/j.jbiomech.2017.08.026

This is a PDF file of an unedited manuscript that has been accepted for publication. As a service to our customers we are providing this early version of the manuscript. The manuscript will undergo copyediting, typesetting, and review of the resulting proof before it is published in its final form. Please note that during the production process errors may be discovered which could affect the content, and all legal disclaimers that apply to the journal pertain. 


\section{In-vivo analysis of sternal angle, sternal and sternocostal kinematics in supine humans during breathing.}

1,2,4,* Benoît Beyer, ${ }^{1,2}$ Véronique Feipel, ${ }^{1,3}$ Victor Sholukha, ${ }^{4}$ Laurence Chèze, ${ }^{1}$ Serge Van Sint Jan.

${ }^{1}$ Laboratory of Anatomy, Biomechanics and Organogenesis (LABO), Université Libre de Bruxelles, Brussels, Belgium

${ }^{2}$ Laboratory of functional anatomy (LAF), Université Libre de Bruxelles, Brussels, Belgium

${ }^{3}$ Department of Applied Mathematics, Peter the Great St.Petersburg Polytechnic University (SPbPU), Russia

${ }^{4}$ Univ Lyon, Université Claude Bernard Lyon 1, Ifsttar, UMR_T9406, LBMC, F69622, Lyon, France

*: Corresponding author. bbeyer@ulb.ac.be; L.A.B.O, Lennik Street 808; CP 619; 1070 Brussel;

Belgium; +32 25556327

Keywords: kinematics, helical axis, thorax, sternocostal, sternal angle

\section{Word count: 3472 words}




\begin{abstract}
This paper aims at contributing to the understanding of the combination of in vivo sternum displacement, sternal angle variations and sternocostal joints (SCJ) kinematics of the seven first rib pairs over the inspiratory capacity (IC). Retrospective codified spiral-CT data obtained at total lung capacity (TLC), middle of inspiratory capacity (MIC) and at functional residual capacity (FRC) were used to compute kinematic parameters of the bones and joints of interest in a sample of 12 asymptomatic subjects. 3D models of rib, thoracic vertebra, manubrium and sternum were processed to determine anatomical landmarks (ALs) on each bone. These ALs were used to create local coordinate system and compute spatial transformation of ribs and manubrium relative to sternum, and sternum relative to thoracic vertebra. The rib angular displacements and associated orientation of rotation axes and joint pivot points (JPP), the sternal angle variations and the associated displacement of the sternum relative to vertebra were computed between each breathing pose at the three lung volumes. Results can be summarized as following: 1) sternum cephalic displacement ranged between 17.8 and $19.2 \mathrm{~mm}$ over the IC; 2) the sternal angle showed a mean variation of $4.4^{\circ} \pm 2.7^{\circ}$ over the IC; 3) ranges of rib rotation relative to sternum decreased gradually with increasing rib level; 4) axes of rotation were similarly oriented at each SCJ; 5) JPP spatial displacements showed less variations at first SCJ compared to levels underneath; 6) linear relation was demonstrated between SCJ ROMs and sternum cephalic displacement over the IC.
\end{abstract}

Keywords: joint kinematics, helical axis, thorax, sternocostal, costovertebral, sternum, sternal angle 


\section{Introduction}

The sternum was demonstrated to participate to rib cage stability (Watkins et al., 2005) and to be related to rib motion during breathing (De Troyer and Decramer, 1985; De Troyer and Wilson, 1993). Sternocostal junctions (SCJ) include two joint components, i.e., the costo-chondral joint and the chondro-sternal joint, that are involved into thorax shape alterations and motion transmission from ribs towards the sternum. The 3D geometry of the ribs, their decreasing ranges-of-motion (ROMs) at costovertebral joints with increasing rib number (Beyer et al., 2014, 2015, Wilson et al., 1987, 2001), and the shape and size differences in costal cartilages seem to have an influence on the coupling between the ribs and sternum during breathing. Thus, the nature of each joint is specific to different regions of the thorax. Indeed, all chondro-sternal joints, but the first one, are synovial joints. The first chondro-sternal joint and all costo-chondral joints show an anatomical and functional continuity between bone and cartilage (i.e., so called synchondrosis joints) (Osmond, 1995). Furthermore, the manubrio-sternal joint (MSJ) is recognized to allow slight variations of the sternal angle (or angle of Louis) as a secondary cartilaginous pliable hinge joint, enabling thorax deformation during deep breathing (Kaneko and Horie, 2012; Osmond, 1995). Previous works have analyzed the mechanical coupling between the ribs and sternum in dog (De Troyer and Decramer, 1985; De Troyer and Wilson, 1993), and concluded that the upper rib cage is tightly linked to the sternum (De Troyer and Decramer, 1985; De Troyer and Wilson, 1993). Similar relation was then observed in 2 high tetraplegic patients (De Troyer et al., 1986). While the relationships between sternum and rib motions are widely recognized, no quantitative data are available in literature, neither on asymptomatic human subjects nor in pathological conditions. Therefore, the aim of the present study was to obtain quantitative analysis of sternal angle variations and the relation between the "true ribs" rotation (i.e., ribs 1 to 7 articulating anteriorly with the sternum) and sternum displacements as a function of lung volume over the inspiratory capacity.

The following hypotheses were tested: 1) the sternal angle changes during breathing motion ; 2) the rib rotation relative to sternum decreases with increasing rib number following costo-vertebral joints pattern (rib rotation relative to vertebrae was previously reported to decrease inversely with rib number (Beyer et al., 2014, 2015; Wilson et al., 2001); 3) the position and orientation of the axes of rib rotation relative to sternum differ between rib levels. 


\section{Materials and method}

\subsection{Sample and data collection}

The protocol included processing and analysis of retrospective codified medical imaging datasets obtained from the Department of Radiology of the Erasme Academic Hospital. Spiral computed tomography (Siemens SOMATOM, helical mode, slice thickness $=0.5 \mathrm{~mm}$, inter-slice spacing $=1 \mathrm{~mm}$, Voxel size: $0.65 * 0.65 * 0.5 \mathrm{~mm}^{3}$, image data format: DICOM 3.0) performed at 3 lung volumes: total lung capacity (TLC), functional residual capacity (FRC) and middle of inspiratory capacity (MIC) which corresponds to FRC $+50 \%$ of the inspiratory capacity (Cassart et al., 1997; Pettiaux et al., 1997). CT images were sequentially performed while the subjects were connected to a spirometer and instructed to maintain inflation at each lung volume of interest while relaxing their respiratory muscle against closed airway (Cassart et al., 1997). A sample of 12 datasets from asymptomatic adults (mean age $31 \pm 6$ years old) was analysed. Details of anthropometric characteristics of the subjects are given in Annex 1.

\subsection{Bone 3D models, anatomical landmarks and local coordinate systems}

From the available CT data, 3D models of ribs, vertebrae, manubrium and sternal body with xiphoid process were obtained using a dedicated data segmentation software (Amira 4.0, San Diego, CA, USA) as previously detailed (Beyer et al., 2014). Models were then imported within a custom-made software called lhpFusionBox (Van Sint Jan et al., 2013) to obtain the spatial coordinates of anatomical landmarks (ALs) located at the surface of the models following previously validated methods for ribs, vertebrae and sternum (Beyer et al., 2014; Van Sint Jan, 2007). Note that all details concerning the ALs are given in Figure 1A.

ALs were then virtually grouped into so-called "AL clouds" that were subsequently used to build anatomical frames (AFs) on each bone of interest. Ribs and vertebrae coordinate systems were obtained as explained in previous analysis of costovertebral joints (Beyer et al., 2014, 2015). Manubrium and sternum AFs are detailed in Figure 1B.

\section{FIGURE 1}

\subsubsection{D kinematic parameters computation}

Note that all rib landmarks clouds were registered in Th7 coordinate system at FRC position chosen as reference position. The displacement of the sternum was computed in the Th7 
coordinate system using change in the position vector of the sternum body relative to the origin of the vertebra coordinate system of interest (i.e. at the midpoint between V1 and V2 in Figure 1). In addition, the sternal angle (also called angle of Louis) is usually described at MSJ level as the angle in the anatomical sagittal plane between the manubrium and the sternal body (Kaneko and Horie, 2012; Osmond, 1995). Therefore, this sternal angle was computed as the angle between the y-axes of the manubrium and sternum coordinate systems (see Figure 1B) at each breathing pose.

The kinematics of ribs AL clouds relative to sternum were computed using rigid body transformation (Söderkvist and Wedin, 1993) and determination of finite helical axis (FHA) including joint pivot point (JPP) (Beyer et al., 2014, 2015; de Lange et al., 1990; Ehrig et al., 2007). The rotation around FHA was used to express rib rotation relative to sternum as a single rotation component. Dispersion of FHA orientations and positions was also computed following previous recommendations (Beyer et al., 2015). FHA positions dispersion was determined from the JPP displacements as following. First, a rectangular parallelepiped that contains (bounds) all of the JPPs was defined, aligned with the ribcage coordinate system. Then, the length of the diagonal of this parallelepiped was calculated to define the dispersion of the JPP as a scalar value.

Finally, the mean helical axis (MHA) at each rib level was computed as the optimal direction vector with the smallest angle between FHA (Stokdijk et al., 1999; Woltring, 1990). Details of the procedure to define spatial position and orientation of MHA in local coordinate systems were previously published (Beyer et al., 2014, 2015). MHA direction cosines in sternum coordinate system were then used to report axes orientation. The location of the mean rotation center (i.e. the mean pivot point (MPP), see (Beyer et al., 2015; Woltring et al., 1985)) was also determined in the sternum coordinate system.

\subsection{Statistical analysis}

Normal distribution of variables was verified using Kolmogorov-Smirnov test. No gender difference in ROM was found (independent t-test). Analysis of variance (ANOVA) for repeated measurements was used to evaluate the influence of the side, rib level and breathing pose on rib kinematics. A one-way ANOVA test was used to analyse the influence of breathing pose on sternal angle. The relation between rib kinematics and sternal displacements was tested using Pearson correlation coefficient (r). Values of $p<0.05$ were considered statistically significant. When ANOVA indicated significant difference for specific factor, Bonferroni post-hoc tests were used to determine the significant comparisons 
at $p<0.05$. A linear regression was conducted to elucidate the relation between sternum axial displacement and SCJ ROMs. Statistical analysis was performed using Statistica software (Statistica 8.0@ StatSoft. Inc., Tulsa, USA).

\section{Results}

All results are given as mean \pm standard errors.

\subsection{Sternum displacement in thoracic vertebra coordinate system}

The mean displacement of the sternum relative to vertebra Th1 was $9.6 \mathrm{~mm} \pm 7.1,17.8 \mathrm{~mm} \pm$ 5.9 and $0.8 \mathrm{~mm} \pm 2.3$ along $\mathrm{x}-, \mathrm{y}$ - and $\mathrm{z}$-axis respectively (see figure 2 ). The displacement occurred mainly in cephalic (y-axis) and, to a lesser extent, anterior (x-axis) directions.

\section{FIGURE 2}

\subsection{Sternal angle variations}

The mean sternal angle was significantly decreasing from $16.7^{\circ} \pm 5.5^{\circ}$ at TLC to $14.9^{\circ} \pm 5.2^{\circ}$ at MIC ( $\mathrm{p}=0.016)$ and to $12.4^{\circ} \pm 4.9^{\circ}(\mathrm{p}=0.0011)$ at FRC. The average ROM of the sternal angle was $4.4^{\circ} \pm 2.7^{\circ}$ similarly distributed above and below MIC with respectively $1.9^{\circ} \pm$ $1.2^{\circ}$ and $2.5^{\circ} \pm 2.1^{\circ}$.

FIGURE 3

\subsection{Rib angular displacement relative to sternum}

Rib1 to Rib7 angular displacements were then all expressed in sternum coordinate system to facilitate comparison and interpretation (see Figure 4). ROMs were significantly influenced by lung volume $(p<0.001)$ and rib level $(p<0.001)$. The interaction between the lung volume and the rib level also had a significant influence $(\mathrm{p}<0.001)$ on ROMs. The total ROMs gradually decreased from $15.5^{\circ} \pm 1.7^{\circ}$ at Rib1 to $7.6^{\circ} \pm 0.8^{\circ}$ at Rib7. Note that Bonferroni post hoc tests demonstrated no significant differences between two to four adjacent rib levels. Above MIC, the ROMs ranged from $4.7^{\circ} \pm 0.9^{\circ}$ at $\mathrm{Rib} 1$ to $3.9^{\circ} \pm 0.7^{\circ}$ at $\mathrm{Rib} 7$ without any significant difference between rib levels. Below MIC, ROMs were gradually decreasing from $10.9^{\circ} \pm 1.8^{\circ}$ at Rib1 to $3.7^{\circ} \pm 0.9^{\circ}$ at Rib7. Note that as between TLC and FRC, no significant ROMs difference was demonstrated between adjacent rib levels (similarly as below MIC). Furthermore, from Rib1 to Rib3, ROMs significantly differed between above and below MIC 
while other lower rib levels (i.e. Rib4 to Rib7) were not altered by lung volume above or below MIC.

\section{FIGURE 4}

\subsection{Dispersion of the FHAs and joint pivot points (JPP)}

Results are presented in figure 5. The dispersion angle between FHAs was not altered by rib level $(p>0.05)$ and ranged between $14.7^{\circ} \pm 1.3^{\circ}$ and $18.5^{\circ} \pm 1.5^{\circ}$. The displacement of the JPP increased significantly with increasing rib number $(p<0.001)$. Note that significant difference $(p<0.01)$ was observed for all rib levels but the first one when compared to the one at Rib2. The mean dispersion of JPP ranged between $28.9 \mathrm{~mm} \pm 3.8$ at Rib2 to $151.3 \mathrm{~mm} \pm 10.6$ at Rib7. Supplementary material 1 gives opportunity to visualize the displacement of each FHA.

\section{FIGURE 5}

\subsection{Mean helical axes orientation and centers of rotation}

All direction cosines for the left bones were mirrored and expressed as right sided to enable comparison between sides. The side had no significant influence on the orientation of MHAs $(p=0.864)$ (see Figure 6).

MHA mean direction cosines ranged between -0.52 and -0.31 on $\mathrm{x}$-axis; between 0.49 and 0.53 on $y$-axis and between 0.35 and 0.56 on z-axis. In other words, the axes were oriented obliquely caudally, ventrally and medially at all rib levels considered (i.e. Rib1 to Rib7). No significant difference were observed between rib levels $(p=0.587)$. The interaction between rib level and $x, y, z$ component did not show any significant influence $(p=0.06)$, confirming that MHA orientation did not change between rib levels. An example of the $3 \mathrm{D}$ visualization obtained is presented in Figure 8 where the left sides MHAs are pointing obliquely caudally, ventrally and medially at each rib level.

\section{FIGURE 6}

The side had no influence on the position of the mean pivot point $(p=0.701)$ while significant differences were observed between rib levels $(p<0.001)$. The position of the MPP was close to $0 \mathrm{~mm}$ on dorso-ventral axis (x-axis), in other words close to the sternum frontal plane, laterally to the sternal body and gradually caudally regarding each rib level. See Figure 7.

\section{FIGURE 7}




\section{FIGURE 8}

\subsection{Relation between rib and sternum displacement}

The range of cephalo-caudal displacement of the sternum was related to the ROMs at SCJ 1 $(r=0.92, p<0.001)$ and SCJ7 $(r=0.74, p=0.006)$. Linear regressions were determined at these 2 levels of interest (see Figure 9). In addition, ROMs obtained in previous study at costovertebral joints (Beyer et al., 2015) were used to test the correlation and linear regression between costovertebral kinematics and cephalic displacement of the sternum. A significant correlation was demonstrated between costovertebral ranges of motion and sternum displacement at $\mathrm{rib} 1(\mathrm{r}=0.95, \mathrm{p}<0.001)$ and $\mathrm{rib} 7(\mathrm{r}=0.81, \mathrm{p}<0.01)$.

\section{FIGURE 9}

\section{Discussion}

The present study describes the sternal displacement, sternal angle variation and sternocostal kinematics between different positions obtained at three different lung volumes on a sample of 12 supine human adults. To the author's best knowledge, this is the first study reporting detailed in-vivo quantification of these specific joints of the human thorax in breathing conditions. The functional role of costal cartilages was previously analyzed in dogs using experimental approach (Fick, 1911) and during in-vitro experimentation (De Troyer and Decramer, 1985; De Troyer and Wilson, 1993). The linkage between sternal displacement and ribs was also described in two tetraplegic patients (De Troyer et al., 1986). Mechanical properties of the costal cartilages and the influence of growth on cartilage geometry were reported in the literature (Andriacchi et al., 1974; Sandoz et al., 2013). However, the present study enabled for the first time to describe quantitative in-vivo human data related to rib and sternum kinematic behavior (i.e. ROM and axes of rotation).

The first major finding concerns averaged variation of $4.4^{\circ}$ observed at the sternal angle. Since the sternal angle increases between each lung volume (see Figure 3), MSJ could act as a torsion spring able to store energy during lung inflation and restore it to facilitate thoracic cage deflation. This is supported by the fact that exhalation is recognized to be a mainly passive mechanism resulting from elastic recoil of mainly the lungs (i.e. pulmonary alveoli) with contribution of chest wall above $75 \%$ of the TLC (Agostoni et al., 1965a; Agostoni and Hyatt, 2011; Osmond, 1995). Note that aging seems to be responsible of altering 
the torsion elastic modulus of cartilaginous joint leading to a decrease in rib cage compliance (Estenne et al., 1985; Sharma and Goodwin, 2006). The increase in sternal angle with increasing lung volume could have been related to the differences in rib length. Indeed, during cephalic displacement of the sternum, the shortest ribs (i.e. rib1 and 2) should lead to a backward shift of the cephalic extremity of the sternum (i.e. manubrium), and by consequence to an increase of the sternal angle.

Another result obtained in this study concerns the gradual decrease of sternocostal ROMs occurring inversely to the analyzed rib level (i.e., the larger the rib level, the smaller the related ROM). As previously underlined (De Troyer and Decramer, 1985), if the rib cage behaved as a rigid entity, all ribs should display equal motions relative to the sternum. However, it was not the case in dogs for which the upper portion of the rib cage was demonstrated to behave more as a unit than the lower ribs (De Troyer and Decramer, 1985; De Troyer and Wilson, 1993). The present study seems to indicate similar behavior in human, and that the rib cage does not move as a rigid entity.

The mechanical linkage between ribs and sternum is highlighted by the variability of both FHAs orientation and position of JPP during breathing motion. From a mechanical aspect, when a joint mechanism is more constrained, the dispersion of FHAs orientation and of JPP position should be smaller. The present result showed that the dispersion of FHAs orientation was similar at all SCJ levels; however, the dispersion of JPP position increased significantly and gradually from Rib1 to Rib7. This finding indicates that the constraint is probably higher at Rib1 and decreases gradually at the rib levels underneath. The supplementary material 1 enables to visualize this finding.

Results of the present study indicates that the conclusion of De Troyer \& Decramer (1985) obtained in dogs largely apply to humans. Note that the decrease in sternocostal ROMs is similar to costovertebral joint motion behavior in breathing (Beyer et al., 2014, 2015; Wilson et al., 1987). Furthermore, the sample used in the present analysis was the same as in previously reported costovertebral joint (CVJ) analysis (Beyer et al., 2014, 2015). Comparing the CVJ and SCJ ROMs, it appears that ROMs were systematically smaller at SCJ than at CVJ levels. This difference in ROMs could be attributed to the difference in MHA orientation at CVJ and SCJ (i.e. which are not parallel) and moreover the small rotation obtained at each intervertebral joint (Beyer et al., 2014).

In addition, the significant influence of lung volume and rib level on SCJ ROMs amplitude is a behavior that was already observed at CVJ levels (Beyer et al., 2016). Similar to CVJs, SCJ ROMs decreased above MIC. Besides, this observation was not true for all rib levels. Indeed, 
only Rib1 to Rib3 showed larger SCJ ROMs below MIC, while Rib4 to Rib7 showed similar ROM above or below MIC. Previous CVJ analysis (Beyer et al., 2015) reported similar ROM decrease above MIC at rib level 1 to 7 . These observations are in agreement with the change in rib cage compliance with increasing lung volume (Agostoni and Hyatt, 2011).

Finally, to the author's knowledge, the orientation of SCJ axes of rotation (i.e., MHAs) was never previously described. MHAs observed in the present study were orientated obliquely, ventrally, downward and inward, and were not influenced by rib level. The computation of rib transformation relative to manubrium gives insight about the cartilages structures in-between. The costal cartilages were positioned close to the sternal frontal plane and gradually oriented downward from the second to the seventh level (Osmond, 1995). The orientation of the first costal cartilage was almost parallel to the 3D oblique orientation of the first MHA. At lower rib levels (Rib2 to Rib7) the MHAs were clearly intersecting the plane of the costal cartilage. Note that the position of the MPP followed the position of the costal cartilage, (see figure 7 along y-axis). Mechanically, MHA orientation variations indicate different costal cartilage behavior during breathing. From a mechanical point of view, when the axis of rotation is following the natural longitudinal axis of a costal cartilage (like for the first costal cartilage), one might assume that such costal cartilage is working as a one degree of freedom torsion bar (or spring) with a torque generated perpendicular to the axis of the bar. However, for lower rib levels (i.e., with MHAs intersecting the cartilage) the torque generated during inflation should be considered around multiple degrees of freedom. These considerations are in agreement with the fact that the first rib is more rigidly attached to the first costal cartilage and to the sternum, but also with the complex morphology of the lower costal cartilages. Thus, it could be considered that the first SCJ is driving the rib cage displacement, and is not able to deform as much as the SCJ underneath.

Some other limitations of the study merit discussion. Results obtained in the present work were determined from an in-vivo sample of young adults (average age $30 \mathrm{yrs}$ ) and should not be generalized to elderly or infants for various reasons. Indeed, previous studies reported that ageing tends to modify both thoracic shape (Gayzik et al., 2008; Joshua et al., 2014; Kent et al., 2005) and material properties of costal cartilages (Forman and Kent, 2014; Guo et al., 2007; Lau et al., 2008). Indeed, costal cartilages often undergo progressive calcification with age (Semine and Damon, 1975) resulting in an increase of cartilage stiffness (Forman and Kent, 2014; Lau et al., 2008) and a decrease in rib cage compliance (Estenne et al., 1985; Sharma and Goodwin, 2006). Following the present interpretation of considering costal 
cartilage as a torsion spring, it is relevant to expect that the change in costal cartilage stiffness with ageing will be translated in a decrease of SCJ ROMs.

Finally, changes in posture have been demonstrated to alter rib cage compliance (Estenne et al., 1985) and supine position was shown to increase rib cage circumference (Agostoni et al., 1965b) by changing the slope of the rib orientation (Sharp et al., 1986). As previously reported (Sharp et al., 1986, p. 1986), these modifications could be adequately explained by the change in orientation of the gravity vector that induce a change in orientation of the gravitational pull exerted on the ribs and their attached structures (i.e. muscles and fascia).

\section{Conclusion}

To the authors' best knowledge, the present study is the first to describe sternocostal joint behavior quantitatively in breathing humans. Reported results are of interest to improve our current understanding related to normal thorax joints physiology and present data should be useful for modelling of respiratory mechanics. Moreover, 3D representation of results enables both qualitative and quantitative kinematics visualization that can be used for pedagogical purposes. Further research will focus on the effect of pathological conditions or treatments on MSJ and SJC kinematics.

\section{Acknowledgement}

The authors thank the Radiology department of Erasme Academic Hospital and Dr Dufresne. The authors are most grateful to Pr. De Troyer for helpful discussions. The authors also thank Mr. L. Campestrini for his contribution during his Master thesis related to the present paper.

\section{Conflict of interest statement}

I declare that all authors that have participated to the study and to the redaction of this manuscript have no financial and personal relationships with other people or organizations that could inappropriately influence this work.

\section{References}

Agostoni, E., Hyatt, R.E., 2011. Static Behavior of the Respiratory System, in: Comprehensive Physiology. John Wiley \& Sons, Inc.

Agostoni, E., Mognoni, P., Torri, G., Agostoni, A.F., 1965a. Static features of the passive rib cage and abdomen-diaphragm. Journal of Applied Physiology 20, 1187-1193. 
Agostoni, E., Mognoni, P., Torri, G., Saracino, F., 1965b. Relation between changes of rib cage circumference and lung volume. J Appl Physiol 20, 1179-1186.

Andriacchi, T., Schultz, A., Belytschko, T., Galante, J., 1974. A model for studies of mechanical interactions between the human spine and rib cage. J Biomech 7, 497-507.

Beyer, B., Sholukha, V., Dugailly, P.M., Rooze, M., Moiseev, F., Feipel, V., Van Sint Jan, S., 2014. In vivo thorax 3D modelling from costovertebral joint complex kinematics. Clin Biomech (Bristol, Avon) 29, 434-438. doi:10.1016/j.clinbiomech.2014.01.007

Beyer, B., Sholukha, V., Salvia, P., Rooze, M., Feipel, V., Van Sint Jan, S., 2015. Effect of anatomical landmark perturbation on mean helical axis parameters of in vivo upper costovertebral joints. J Biomech 48, 534-538. doi:10.1016/j.jbiomech.2014.12.035

Beyer, B., Van Sint Jan, S., Chèze, L., Sholukha, V., Feipel, V., 2016. Relationship between costovertebral joint kinematics and lung volume in supine humans. Respir Physiol Neurobiol 232, 57-65. doi:10.1016/j.resp.2016.07.003

Cassart, M., Pettiaux, N., Gevenois, P.A., Paiva, M., Estenne, M., 1997. Effect of chronic hyperinflation on diaphragm length and surface area. Am. J. Respir. Crit. Care Med. $156,504-508$.

de Lange, A., Huiskes, R., Kauer, J.M., 1990. Effects of data smoothing on the reconstruction of helical axis parameters in human joint kinematics. J Biomech Eng 112, 107-113.

De Troyer, A., Decramer, M., 1985. Mechanical coupling between the ribs and sternum in the dog. Respiration Physiology 59, 27-34. doi:doi/10.1016/0034-5687(85)90015-5

De Troyer, A., Estenne, M., Vincken, W., 1986. Rib cage motion and muscle use in high tetraplegics. Am. Rev. Respir. Dis. 133, 1115-1119.

De Troyer, A., Wilson, T.A., 1993. Sternum dependence of rib displacement during breathing. Journal of applied physiology 75, 334-340.

Ehrig, R.M., Taylor, W.R., Duda, G.N., Heller, M.O., 2007. A survey of formal methods for determining functional joint axes. $J$ Biomech 40, 2150-2157. doi:10.1016/j.jbiomech.2006.10.026

Estenne, M., Yernault, J.C., Troyer, A.D., 1985. Rib cage and diaphragm-abdomen compliance in humans: effects of age and posture. Journal of Applied Physiology 59, 1842-1848.

Fick, R., 1911. Handbuch der Anatomie und Mechanik der Gelenke T. 3. T. 3. Fischer, Jena.

Forman, J.L., Kent, R.W., 2014. The effect of calcification on the structural mechanics of the costal cartilage. Comput Methods Biomech Biomed Engin 17, 94-107. doi:10.1080/10255842.2012.671307

Gayzik, F.S., Yu, M.M., Danelson, K.A., Slice, D.E., Stitzel, J.D., 2008. Quantification of age-related shape change of the human rib cage through geometric morphometrics. Journal of Biomechanics 41, 1545-1554. doi:10.1016/j.jbiomech.2008.02.006 
Guo, B., Liao, D., Li, X., Zeng, Y., Yang, Q., 2007. Age and gender related changes in biomechanical properties of healthy human costal cartilage. Clinical Biomechanics 22, 292-297. doi:10.1016/j.clinbiomech.2006.10.004

Joshua, A., Shetty, L., Pare, V., 2014. Variations in Dimensions and Shape of Thoracic Cage with Aging: An Anatomical Review. Anatomy Journal of Africa 3, 346-355.

Kaneko, H., Horie, J., 2012. Breathing Movements of the Chest and Abdominal Wall in Healthy Subjects. Respir Care 57, 1442-1451. doi:10.4187/respcare.01655

Kent, R., Lee, S.-H., Darvish, K., Wang, S., Poster, C.S., Lange, A.W., Brede, C., Lange, D., Matsuoka, F., 2005. Structural and material changes in the aging thorax and their role in crash protection for older occupants. Stapp Car Crash J 49, 231-249.

Lau, A., Oyen, M.L., Kent, R.W., Murakami, D., Torigaki, T., 2008. Indentation stiffness of aging human costal cartilage. Acta Biomaterialia 4, 97-103. doi:10.1016/j.actbio.2007.06.008

Osmond, D.G., 1995. Functionnal anatomy of the chest wall, in: The Thorax: Part A, 2nd Ed. Roussos C., New York, pp. 413-444.

Pettiaux, N., Cassart, M., Paiva, M., Estenne, M., 1997. Three-dimensional reconstruction of human diaphragm with the use of spiral computed tomography. J. Appl. Physiol. 82, 998-1002.

Sandoz, B., Badina, A., Laporte, S., Lambot, K., Mitton, D., Skalli, W., 2013. Quantitative geometric analysis of rib, costal cartilage and sternum from childhood to teenagehood. Med Biol Eng Comput 51, 971-979. doi:10.1007/s11517-013-1070-5

Semine, A.A., Damon, A., 1975. Costochondral Ossification and Aging in Five Populations. Human Biology 47, 101-116.

Sharma, G., Goodwin, J., 2006. Effect of aging on respiratory system physiology and immunology. Clin Interv Aging 1, 253-260.

Sharp, J.T., Beard, G.A., Sunga, M., Kim, T.W., Modh, A., Lind, J., Walsh, J., 1986. The rib cage in normal and emphysematous subjects: a roentgenographic approach. J. Appl. Physiol. 61, 2050-2059.

Söderkvist, I., Wedin, P.A., 1993. Determining the movements of the skeleton using wellconfigured markers. J Biomech 26, 1473-1477.

Stokdijk, M., Meskers, C.G., Veeger, H.E., de Boer, Y.A., Rozing, P.M., 1999. Determination of the optimal elbow axis for evaluation of placement of prostheses. Clin Biomech (Bristol, Avon) 14, 177-184.

Van Sint Jan, 2007. Color atlas of skeletal landmark definitions: guidelines for reproducible manual and virtual palpations. Churchill Livingstone/Elsevier, Edinburgh ; New York.

Van Sint Jan, S., Wermenbol, V., Van Bogaert, P., Desloovere, K., Degelaen, M., Dan, B., Salvia, P., Ortibus, E., Bonnechère, B., Le Borgne, Y.-A., Bontempi, G., Vansummeren, S., Sholukha, V., Moiseev, F., Rooze, M., 2013. A technological 
platform for cerebral palsy - The ICT4Rehab project. Médecine/Sciences 29, 529-536. doi:10.1051/medsci/2013295017

Watkins, R., 4th, Watkins, R., 3rd, Williams, L., Ahlbrand, S., Garcia, R., Karamanian, A., Sharp, L., Vo, C., Hedman, T., 2005. Stability provided by the sternum and rib cage in the thoracic spine. Spine 30, 1283-1286.

Wilson, T.A., Legrand, A., Gevenois, P.A., De Troyer, A., 2001. Respiratory effects of the external and internal intercostal muscles in humans. J. Physiol. (Lond.) 530, 319-330.

Wilson, T.A., Rehder, K., Krayer, S., Hoffman, E.A., Whitney, C.G., Rodarte, J.R., 1987. Geometry and respiratory displacement of human ribs. J. Appl. Physiol. 62, 1872 1877.

Woltring, H.J., 1990. Biomechanics of Human Movement, Applications in Rehabilitation, Sport and Ergonomics; Biomechanics of Human Movement, Applications in Rehabilitation, Sport and Ergonomics 203-237.

Woltring, H.J., Huiskes, R., de Lange, A., Veldpaus, F.E., 1985. Finite centroid and helical axis estimation from noisy landmark measurements in the study of human joint kinematics. J Biomech 18, 379-389. 
Figure 1: A: Anatomical landmarks (ALs) located on vertebrae, ribs, manubrium and sternum. For ribs and vertebrae: see Beyer et al, 2015, 2016; For manubrium: M1: uppermost point of the right clavicular surface, M2: uppermost point of the left clavicular surface, M3: central point of the jugular notch, M4: at the center of manubriosternal edge on the manubrium, For sternum body: S1: on the right top of the $2^{\text {nd }}$ chondro-sternal surface, S2: on the left top of the $2^{\text {nd }}$ chondro-sternal surface, S3: at the center of manubriosternal edge on the sternum (mirror of M4), S4: at the center of the lowermost extremity of the sternum at xyphisternal joint.

B: Anatomical coordinate systems used to describe displacements. For manubrium: y-axis (cephalocaudal, in green) was computed between M4 and M3 (along the body of the manubrium), z-axis (lateral to the right, in blue) between $\mathrm{M} 2$ and $\mathrm{M} 1$, and $\mathrm{x}$-axis (dorso-ventral, in red) normal to others and pointing forward. For sternum: $y$-axis was computed between $\mathrm{S} 4$ and $\mathrm{S3}$ along the sternum body, z-axis between $\mathbf{S 2}$ and $\mathbf{S 1}$ normal to $\mathbf{y}$-axis, and $\mathbf{x}$-axis normal to others pointing forward. The sternal angle (angle of Louis) was calculated as the angle between manubrium and sternum y-axes within the sagittal plane. For ribs and vertebrae: see Beyer et al, 2015, 2016

Figure 2: Sternal displacement relative Th7 coordinate systems. Results are presented according to each axis of the coordinate systems in millimeters +/- standard errors.

Figure 3: Sternal angle variations between each available lung volume in degree $\left({ }^{\circ}\right)$. Black stars represent significant difference $(p<0.05)$ between lung volumes. Vertical bars denote $+/$ - standard errors.

Figure 4: Rib1 to Rib7 ROMs between each available lung volume. Results are presented in degree $\left(^{\circ}\right)$ in the sternum coordinate system. Vertical bars denote $+/$ - standard errors.

Figure 5: A: Dispersion of FHAs in degree at each rib level regardless of the side. Results are expressed in degree $\left({ }^{\circ}\right)$, vertical bars denote $+/$ - standard errors.

B: Displacement of JPP. Results correspond to the norm of the vector that represents the "bounding box" in millimeter. Vertical bars denote $+/$ - standard errors.

Figure 6: A: MHA direction cosines according sternal coordinate system. Note that direction cosines of left ribs were mirrored and expressed as right ribs. Results are presented as mean direction cosines; vertical bars denote $+/$ - standard errors.

Figure 7: Position of the mean pivot point in sternum coordinate system. Data are presented in millimeter +/- 0.95 confidence intervals along each axis of the sternal frame. Note that left sided rotation centers were mirrored to right side to allow comparison. 
Figure 8: 3D representation of mean helical axes (MHAs), anatomical frames and bones of interest observed in this study. Because they were not clearly visible in the original CT datasets used for this study, costal cartilages were approximated as straight lines between the anterior extremity of the rib and the insertion site on the sternum body or manubrium. The mean pivot point is displayed as a ball on each MHA. A: Frontal plane B: Sagittal plane. 3D visualization of finite helical axes during breathing motion is available in supplementary material 2.

Figure 9: Rib angular displacement as a function of cephalo-caudal displacement of the sternum at costovertebral joint (A) and sternocostal joint (B). Results are given for each of the 12 subjects, at uppermost rib1 and lowermost rib7. Ranges of motions are expressed in degree and sternum displacement in millimeter. 
FIGURE 1
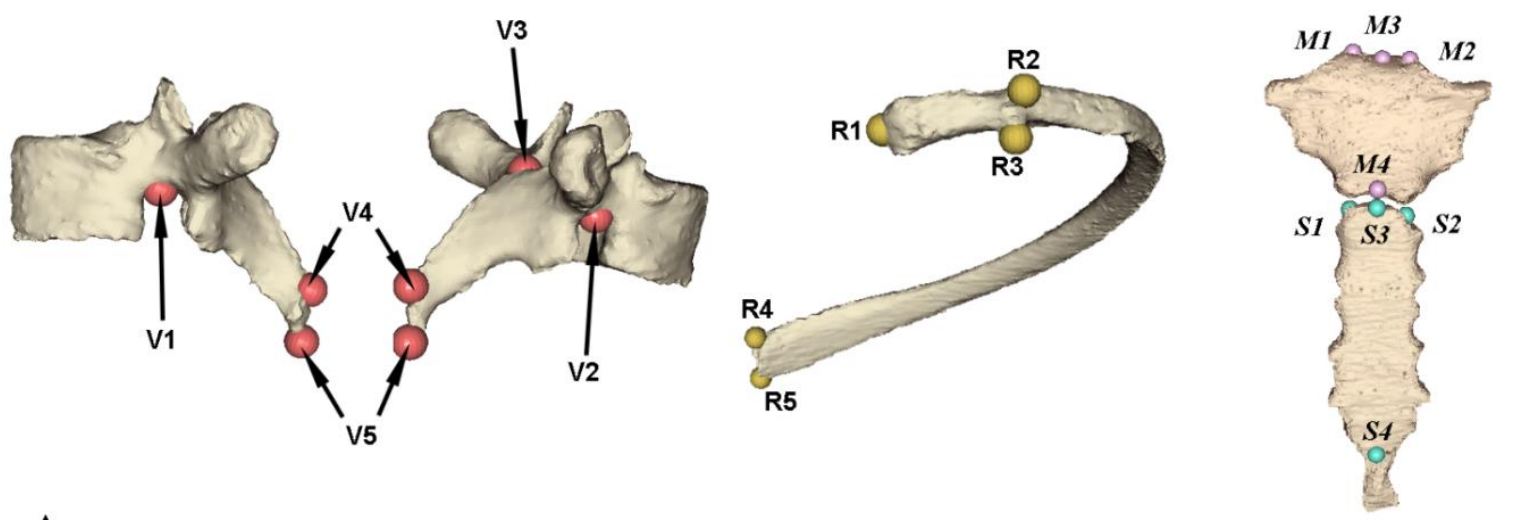

A
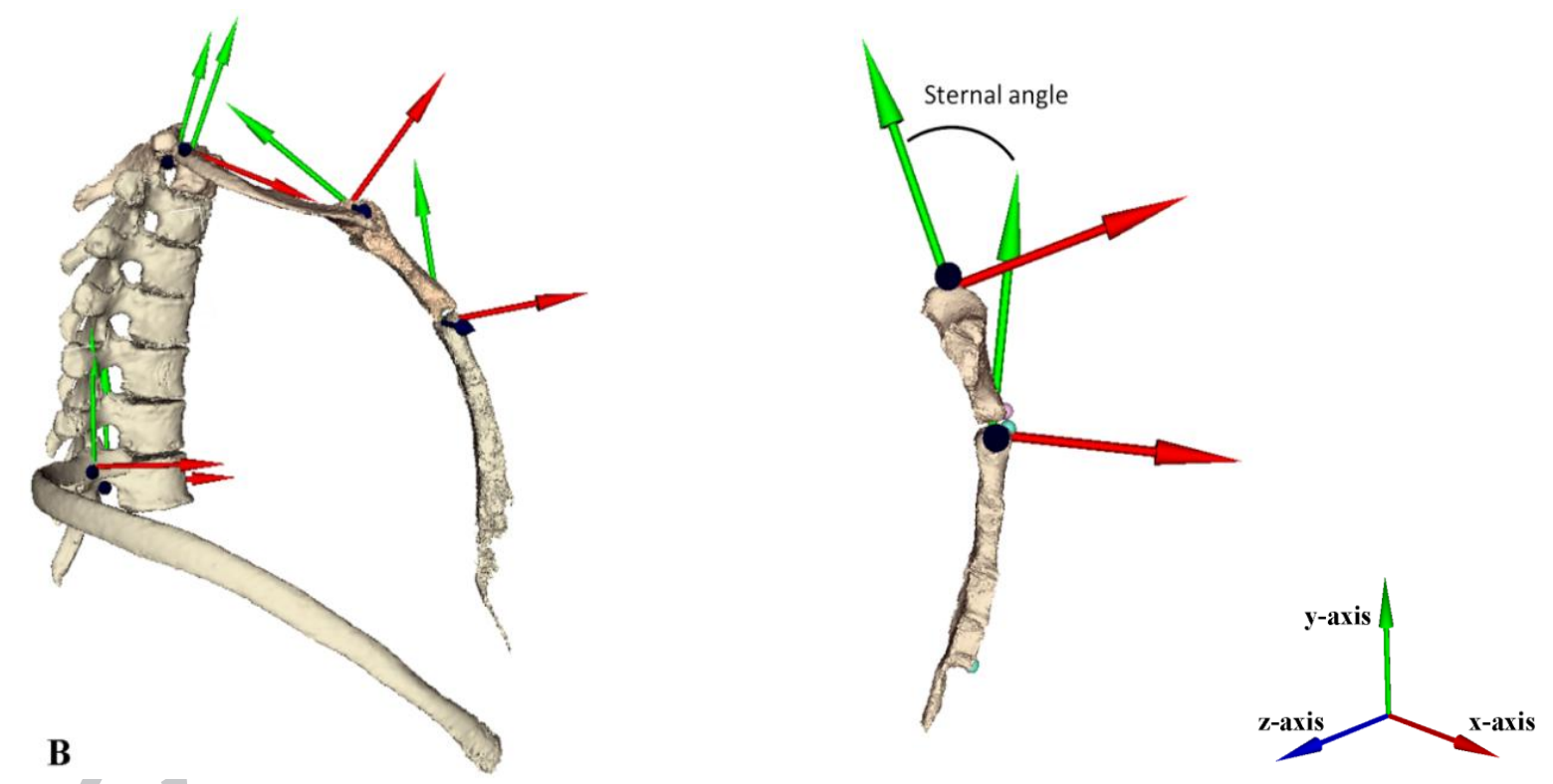
FIGURE 2
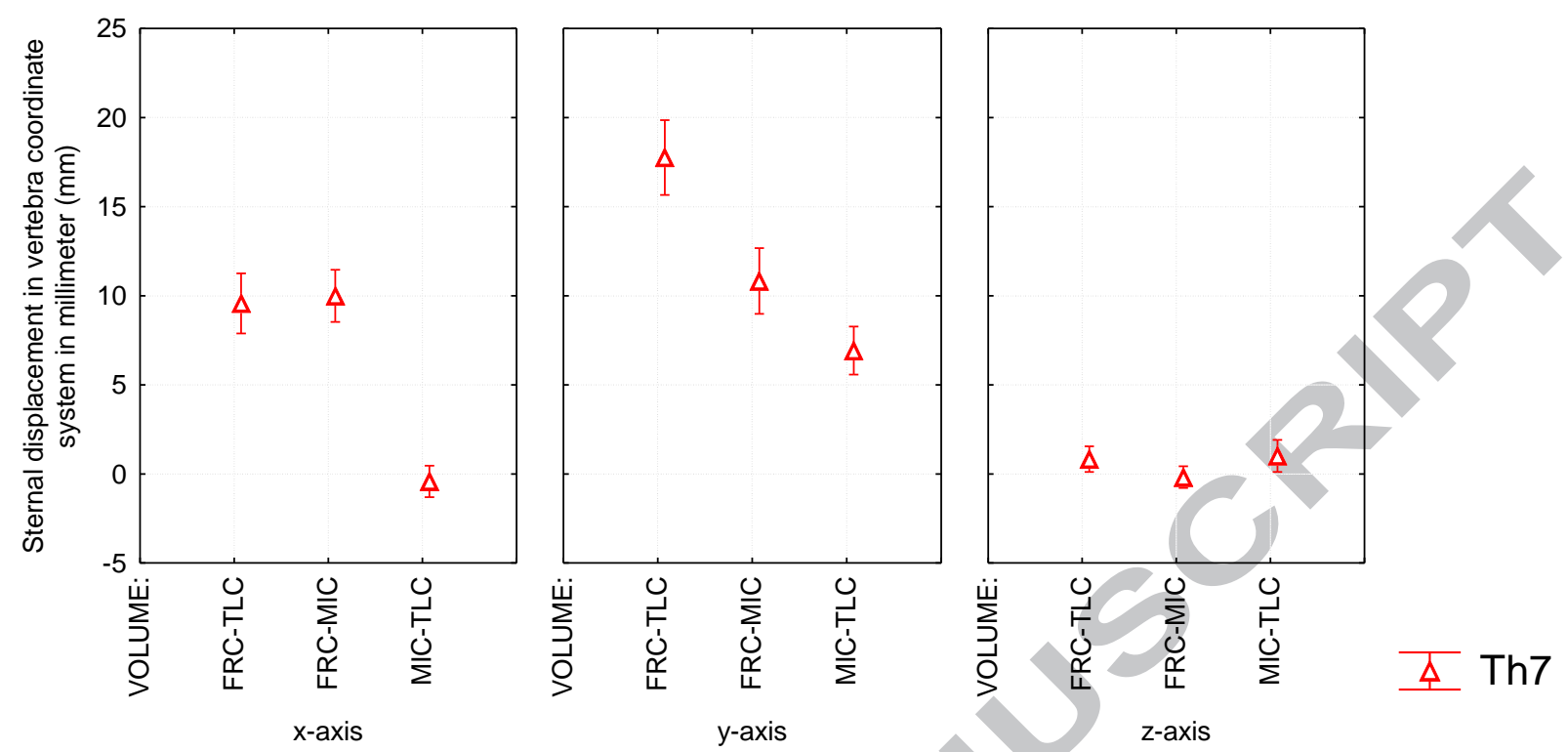
FIGURE 3

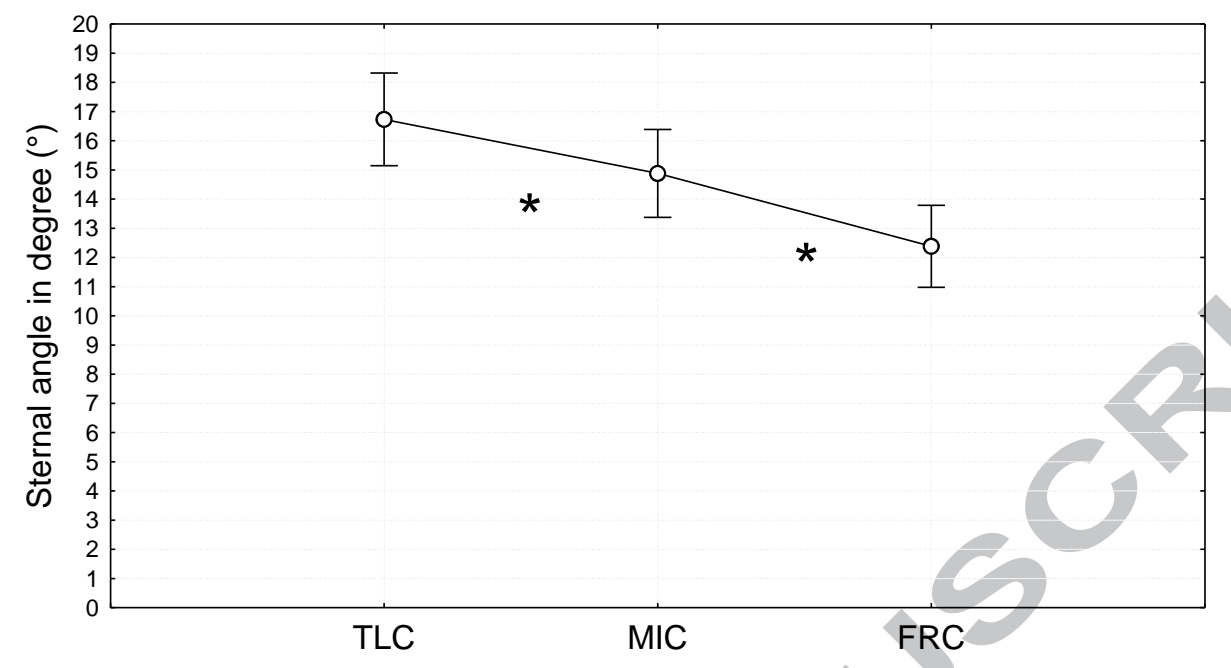




\section{FIGURE 4}

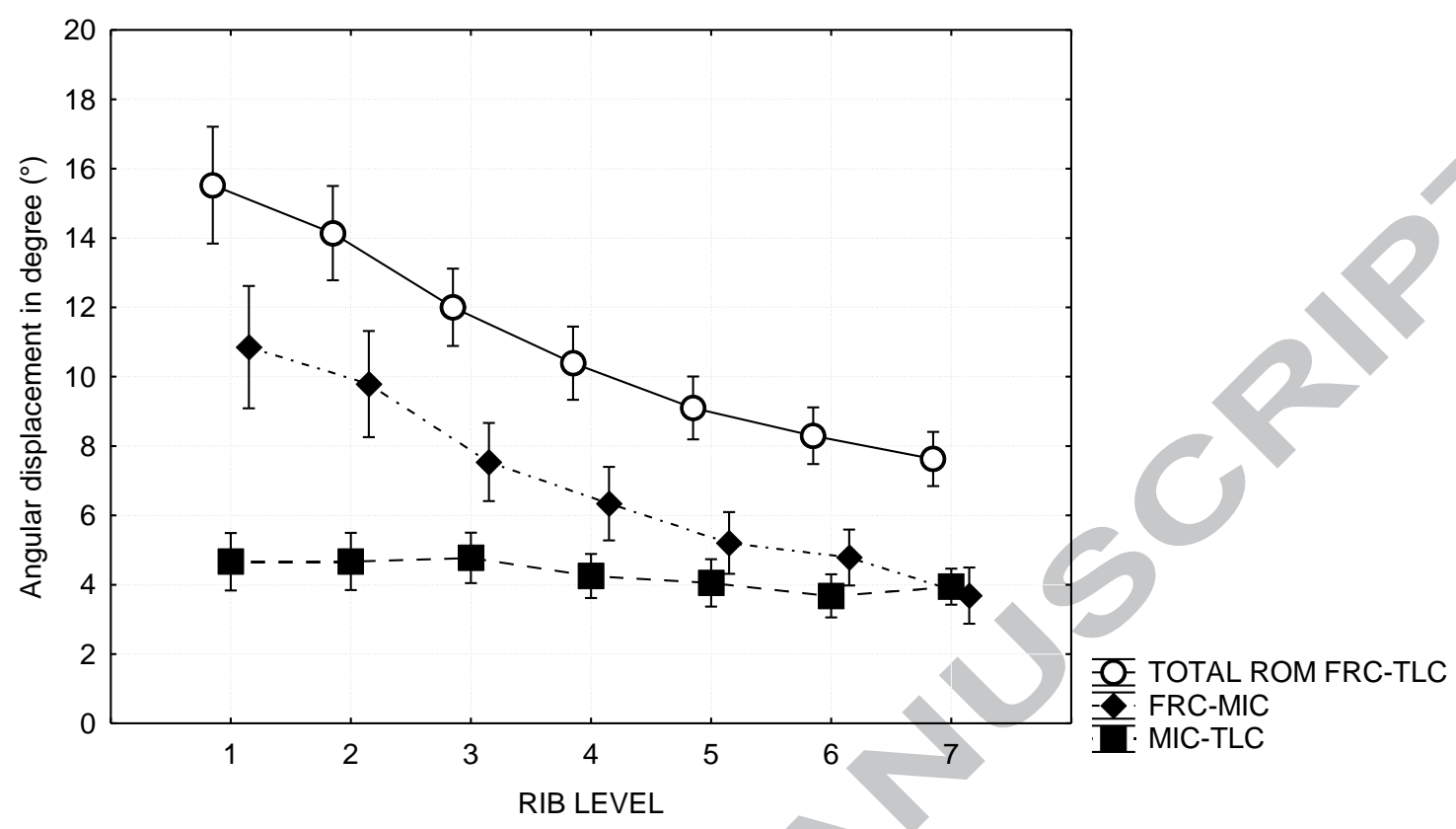




\section{FIGURE 5}

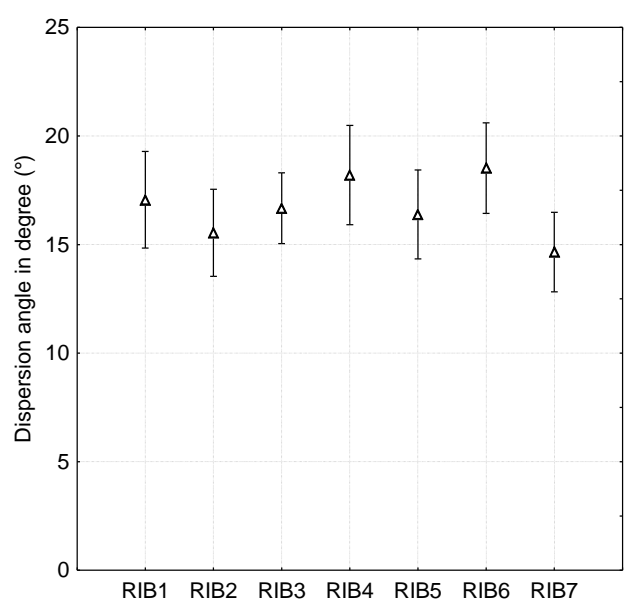

A

RIB1 RIB2 RIB3 RIB4 RIB5 RIB6 RIB7

B

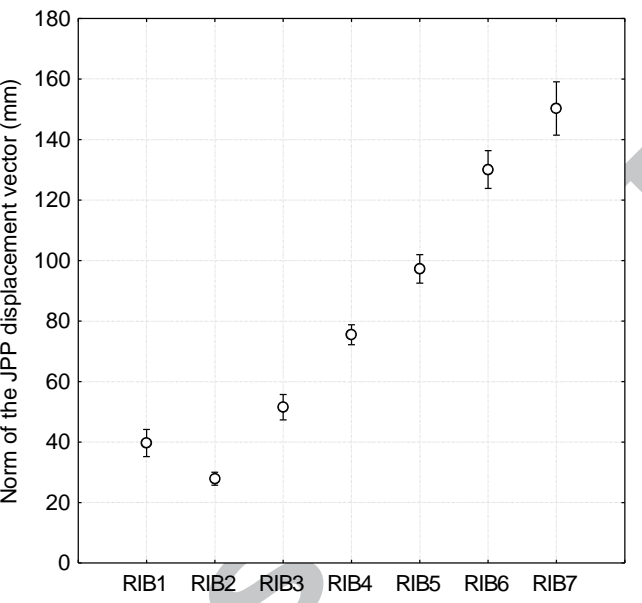




\section{FIGURE 6}
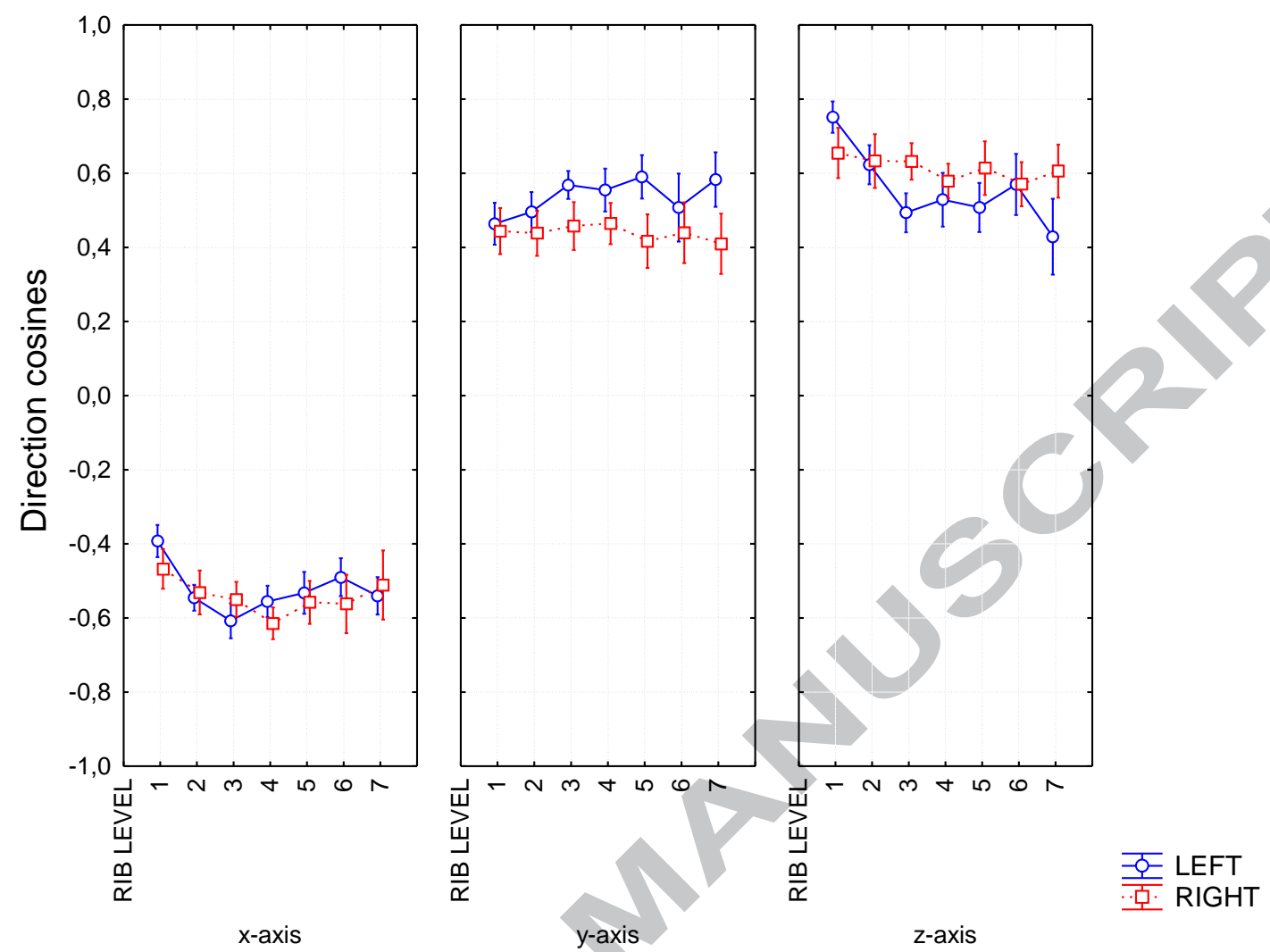


\section{FIGURE 7}
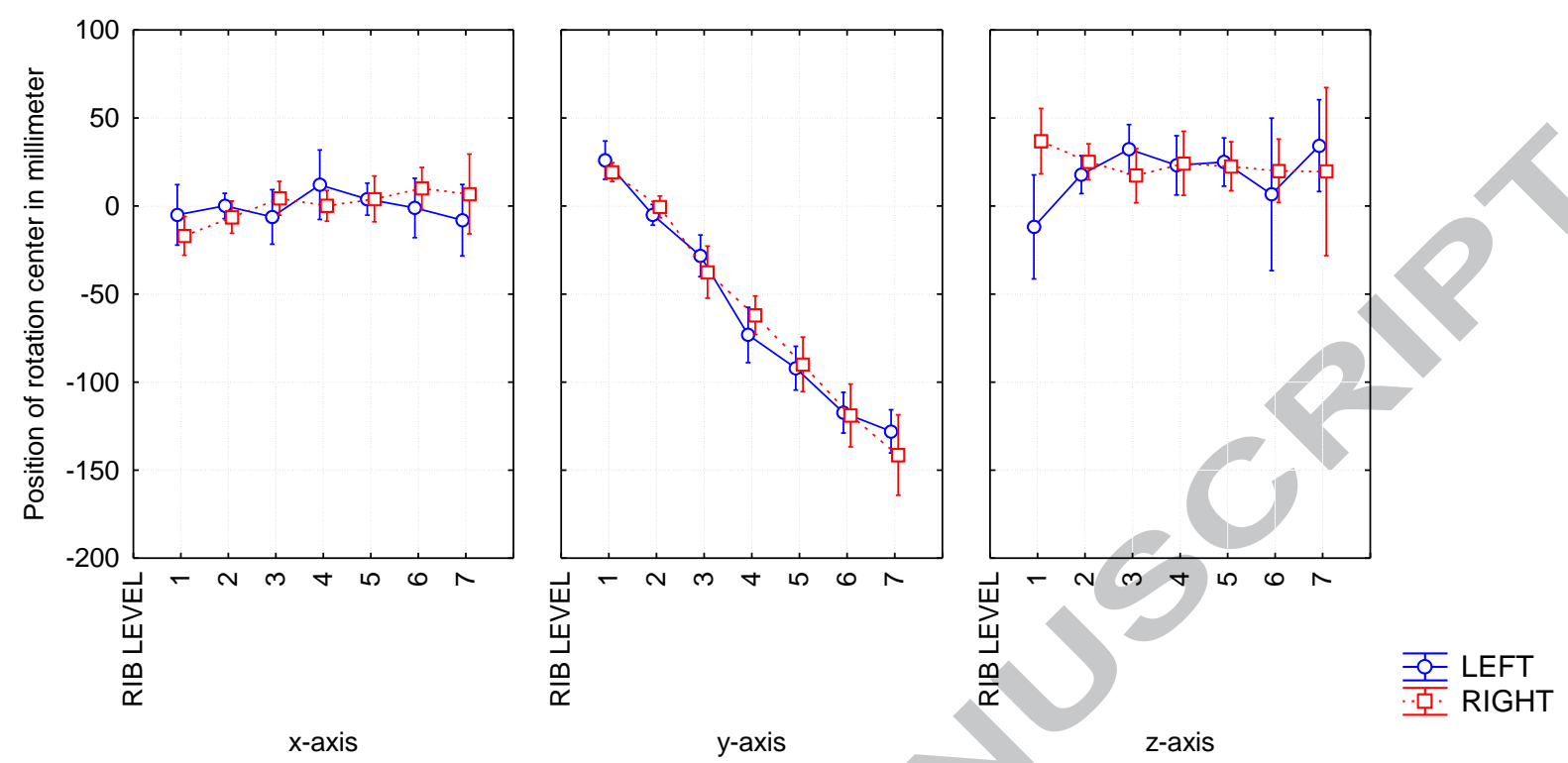
FIGURE 8
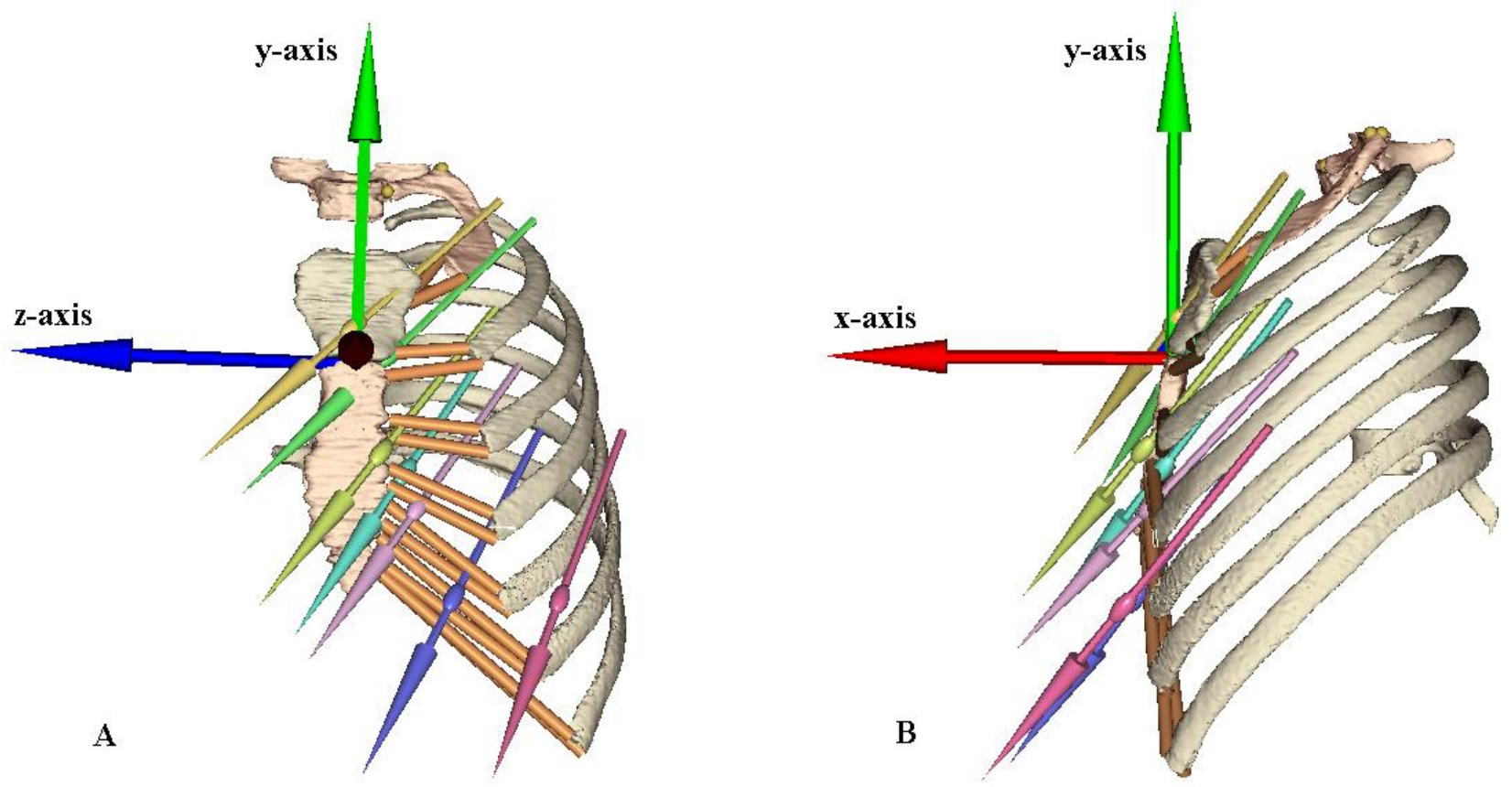
FIGURE 9

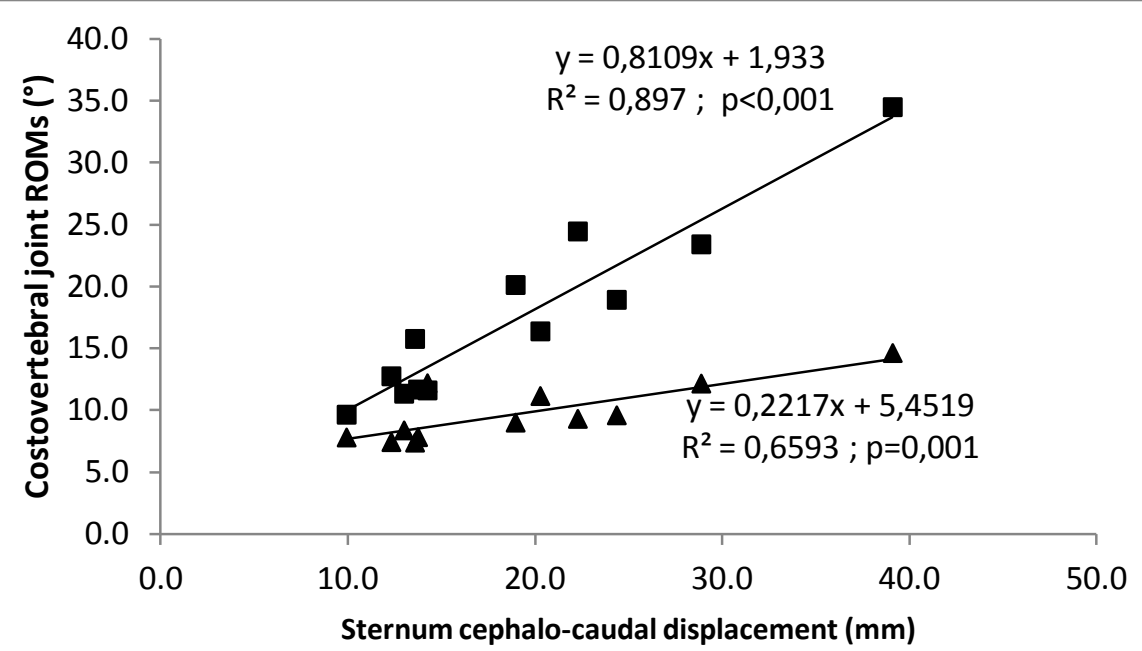

CVJ1

A

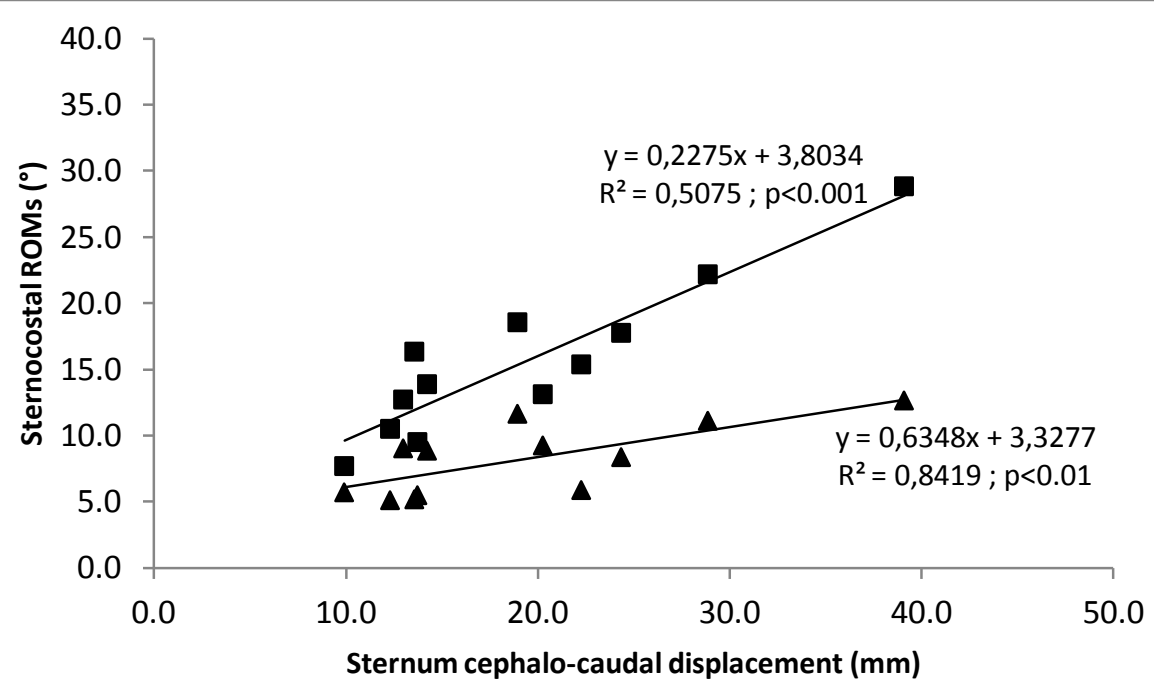

B 


\begin{tabular}{cccc}
\hline Age, yr & 30 & \pm & 6 \\
Sex, M/F & $7 / 5$ & & \\
Height, cm & 171 & \pm & 8 \\
Weight, kg & 63 & \pm & 13 \\
TLC, 1 & 6.25 & \pm & 1.1 \\
MIC, 1 & 4.86 & \pm & 0.7 \\
FRC, 1 & 3.44 & \pm & 0.43 \\
IC, 1 & 2.82 & \pm & 0.87 \\
FEV 1 & 3.70 & \pm & 0.84 \\
Thoracic index at Th3 & 28.1 & \pm & 3.7 \\
Thoracic index at Th7 & 41.0 & \pm & 6.1 \\
Th1-Th7 height, cm & 12.9 & \pm & 0.7 \\
\hline
\end{tabular}

Annex 1: Anthropometric and functional characteristics of the subjects. Values are means \pm SD. All lung volumes were measured seated during functional pulmonary tests.

Thoracic height was computed as distance between $\mathrm{V} 3$ landmark of Th1 and Th7 at functional residual capacity. Thoracic indices were measured in sagittal plane at $\mathbf{T h 1}$ and Th7 at FRC following Bellemare et al, 2001, as follows: (Anteroposterior / Lateral diameter)*100. 